\title{
Enhancement of Lipid Production from Ankistrodesmus sp.
}

\author{
K. Sukkrom, B. Bunnag, and P. Pavasant
}

\begin{abstract}
Ankistrodesmussp. was cultivated for the production of microalgal lipid. It was proven that batch culture provided a better biomass and lipid productivities than continuous cultures where the achievable maximum cell and lipid productivities were 279.80 and $87.10 \mathrm{mg} \mathrm{L}^{-1} \mathrm{~d}^{-1} \cdot \mathrm{pH}$ in the range from 6 to 8 was not found to give significant effects on growth and lipid production where the culture seemed to grow best at pH 8. Although the algal growth remained unaltered, lipid production could be enhanced when the culture was aerated with additional $\mathrm{CO}_{2}$. It was found that as much as $30 \%$ lipid could be enhanced when $5 \%$ by vol. of $\mathrm{CO}_{2}$ was mixed with the air supply, i.e. lipid productivity increased from 87.10 to $104.43 \mathrm{mg} \mathrm{L}^{-1} \mathrm{~d}^{-1}$. Analysis indicates that $\mathrm{CO}_{2}$ helped promote the accumulation of palmitic acid which is the dominant lipid species.
\end{abstract}

Index Terms-Ankistrodesmus sp., lipid production, continuous culture, carbon dioxide.

\section{INTRODUCTION}

A deplete in natural resources especially fossil fuels has stimulated a global concern on material recycle, waste minimization and particularly renewable/alternative energy sources such as geothermal, wind, solar, hydro-energy, and bioenergy [1]. Bioenergy poses one of the most potential energy alternatives and biodiesel has been promoted as diesel substitute in several countries. Biodiesel is non-toxic, biodegradable, renewable and free from sulfur and aromatics. Biodiesel is usually produced from vegetable oils including rapeseed, soybean, mustard, palm, sunflower, algae and animal fats such as tallow, lard and yellow grease. Much attention has been paid to biodiesel production from vegetable oils and animal fats, and a recent attention has been given to the aquatic algal biomass due to its potential high productivity. Many research reports stated that microalgae provided a much greateroil productivity per unit area when compared with other plant sources. Microalgae can also be grown rapidly in various types of environments. These several benefits support the future promotion of algae as biodiesel source. This will not only help achieve environmental and economic sustainability, but the algal cultivation is also capable of sequestering atmospheric carbon dioxide $\left(\mathrm{CO}_{2}\right)$ and lessens the global warming problem.

Manuscript received May 26, 2014; revised July 11, 2014.

K. Sukkrom is with the Joint Graduate School of Energy and Environment, King Mongkut's University ofTechnology Thonburi, Bangkok, Thailand (e-mail: katiesweetcity@gmail.com).

B. Bunnag is with Pilot Plant Development and Training Institute, King Mongkut's University of Technology Thonburi, Bangkok, Thailand (e-mail: boosya.bun@kmutt.ac.th).

P. Pavasant is with the Department of Chemical Engineering, Faculty of Engineering, Chulalongkorn University, Bangkok, Thailand (e-mail: prasert.p@chula.ac.th).
Recently, Maeda et al. [2] used the chemostat and turbidostat methods to evaluate effects of turbidity and dilution rate on lipid production rate of Chlamydomonas sp., Lamers et al. [3] used the turbidostat mode to study the effect of light intensity on fatty acid metabolism of the alga Dunaliellasalina in a flat panel photobioreactor. Tang et al. [4] studied the influences of light intensity, $\mathrm{CO}_{2}$ concentration on the growth, lipid content, and fatty acid composition of Dunaliellatertiolecta and Chlorella minutissima. They reported that both microalgae had the high growth rate and suitable fatty acid profile as biodiesel feedstock.

Ankistrodesmus sp. is unicellular green microalgae with the total lipid content of up to $24 \%$ [5]. Ankistrodesmusfusiformis and Ankistrodesmusfalcatus showed the high lipid content and high levels of polyunsaturated FAME, which could be used in the production of biodiesels with the lowest cetane number (42.47-50.52), the highest iodine values (101.33-136.97) and the lowest oxidation stability [6] and [7]. Ankistrodesmusfalcatus contained C16:0, C18:1 and C18:3 as their major fatty acid components. Furthermore, Ankistrodesmus sp. could effectively utilize $\mathrm{CO}_{2}$ for its growth [8]. This could be applied as a $\mathrm{CO}_{2}$ mitigation mechanism for the removal of greenhouse gases emitted from power plants.

This study examined the lipid production from Ankistrodesmussp. which was cultivated in an airlift photobioreactor. This started from the investigation on the mode of biomass production, i.e. batch and continuous cultures, followed by the study of the effect of environmental/operating conditions on the stimulation of algal lipid. aims to investigate the effect of $\mathrm{pH}$, carbon dioxide concentration in batch culture and dilution rate in continuous culture.

\section{METHODS}

\section{A. Microalgal Strain, Medium and Photobioreactor}

Ankistrodesmus sp.was obtained fromMicrobiological Resources Centre (MIRCEN) of Thailand Institute of Science and Technology Research (TISTR).Ankistrodesmus sp.was cultured with BG11 medium which contained the components as follows (per liter): $1.5 \mathrm{~g} \mathrm{NaNO}_{3}, 0.04 \mathrm{~g}$ $\mathrm{K}_{2} \mathrm{HPO}_{4} \cdot 3 \mathrm{H}_{2} \mathrm{O}, 0.075 \mathrm{~g} \mathrm{MgSO}_{4} \cdot 7 \mathrm{H}_{2} \mathrm{O}, 0.036 \mathrm{~g} \mathrm{CaCl}_{2} \cdot 2 \mathrm{H}_{2} \mathrm{O}$, $0.006 \mathrm{~g}$ Citric acid, $0.006 \mathrm{~g}$ Ammonium ferric citrate, $0.001 \mathrm{~g}$ EDTANa $2,0.02 \mathrm{~g} \mathrm{NaCO}_{3}$. Microelement was prepared in the following composition (per liter): $2.86 \mathrm{mg} \mathrm{H}_{3} \mathrm{BO}_{3}, 1.81 \mathrm{mg}$ $\mathrm{MnCl}_{2} \cdot 4 \mathrm{H}_{2} \mathrm{O}, \quad 0.22 \quad \mathrm{mg} \quad \mathrm{ZnSO}_{4} \cdot 7 \mathrm{H}_{2} \mathrm{O}, \quad 0.39 \quad \mathrm{mg}$ $\mathrm{Na}_{2} \mathrm{MoO}_{4} \cdot 2 \mathrm{H}_{2} \mathrm{O}, 0.08 \mathrm{mg} \mathrm{CuSO}_{4} \cdot 5 \mathrm{H}_{2} \mathrm{O}$ and $0.05 \mathrm{mg}$ $\mathrm{Co}\left(\mathrm{NO}_{3}\right)_{2} \cdot 6 \mathrm{H}_{2} \mathrm{O}$. The incubation was carried out in $250 \mathrm{~mL}$ 
flask for one week before transferred to the $3 \mathrm{~L}$ internal loop airlift photobioreactor which was made of clear acrylic plastic with the following dimension:column height of $60 \mathrm{~cm}$ and $10 \mathrm{~cm}$ i.d.(wall thickness $3 \mathrm{~mm}$ ), draft tube height of 40 $\mathrm{cm}$ and $5 \mathrm{~cm}$ i.d. (wall thickness $2 \mathrm{~mm}$ ). Air was provided at the bottom of the photobioreactor. The cultivation was carried out both in batch and continuous modes, both under a controlled temperature environment $\left(30^{\circ} \mathrm{C}\right)$ in the evaporative chamber where light intensity was provided by fluorescent lamps at 30,000 lux $\left(405 \mu \mathrm{mol} \mathrm{m} \mathrm{m}^{-2} \mathrm{~s}^{-1}\right)$. For continuous cultures, fresh BG11 medium was added into the system continuously through a peristaltic pump. The spent medium and microalgae overflowed to the product tank while the volume of solution in reactor was maintained at $3 \mathrm{~L}$. The operation of the continuous cultivation is shown in Fig. 1.

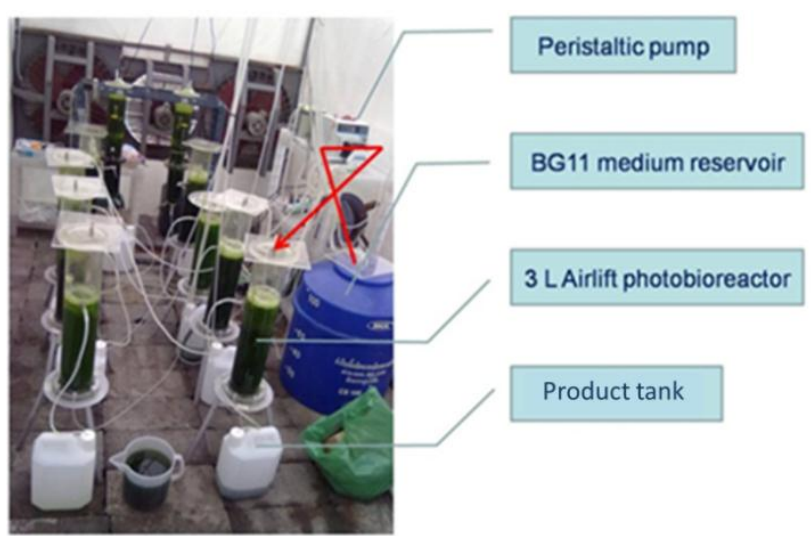

Fig. 1. Continuous cultivation of Ankistrodesmus sp.

\section{B. pH Control System}

Fig. 2 shows a schematic drawing of the photobioreactor with $\mathrm{pH}$ control. It consisted of the airlift photobioreactor connected to a carbon dioxide tank. A pH electrode in the culture airlift photobioreactor was coupled to a $\mathrm{pH}$ controller. $\mathrm{pH}$ was measured continually, and kept within an interval of $6 \pm 0.5,7 \pm 0.5$ and $8 \pm 0.5$ by automatic $\mathrm{CO}_{2}$ feeding.

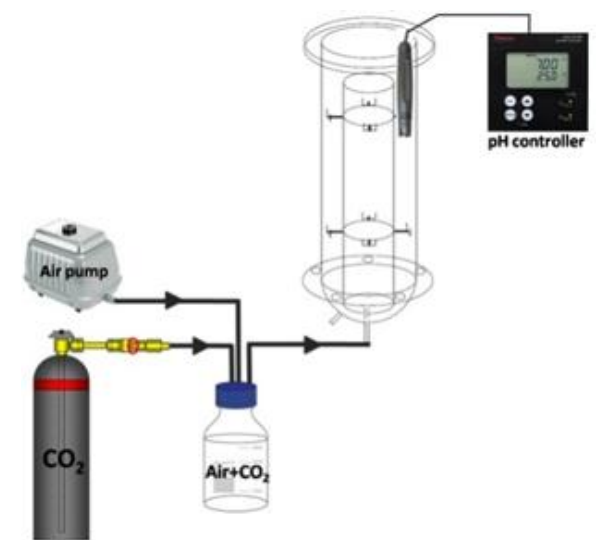

Fig. 2. Schematic of experiment set up of the $\mathrm{pH}$ controlled photobioreactor.

\section{RESULTS}

\section{A. Comparison between Batch and Continuous Cultivation}

Fig. 3 shows the results from the batch and continuous cultivations of Ankistrodesmus sp. The continuous culture was subject to the operation at various dilution rates, i.e. 0.08 , 0.16 and $0.24 \mathrm{~d}^{-1}$. The cell density of Ankistrodesmus sp. obtained from the batch cultivation at the last day was $2.32 \mathrm{~g}$
$\mathrm{L}^{-1}$, while the average of cell density from the continuous operation were $1.02,0.79$ and $0.53 \mathrm{~g} \mathrm{~L}^{-1}$ at the three dilution rates respectively.

The continuous culture started with the dilution rate of $0.08 \mathrm{~d}^{-1}$, and as the culture reached its pseudo steady state (approximately 10 days), the dilution rate was increased 2-fold from 0.08 to $0.16 \mathrm{~d}^{-1}$ during Days $11-22$ of cultivation. During this second period, biomass decreased and became steady after Day 17 (from 1.25 to $0.79 \mathrm{~g} \mathrm{~L}^{-1}$ ). At days 23-33 of cultivation, the dilution rate was further adjusted to 0.24 $\mathrm{d}^{-1}$. At first, Ankistrodesmus sp. increased slowly, but later decreased which was expected from the high dilution rate. The growth reached steady state during the last 5 days of cultivation.

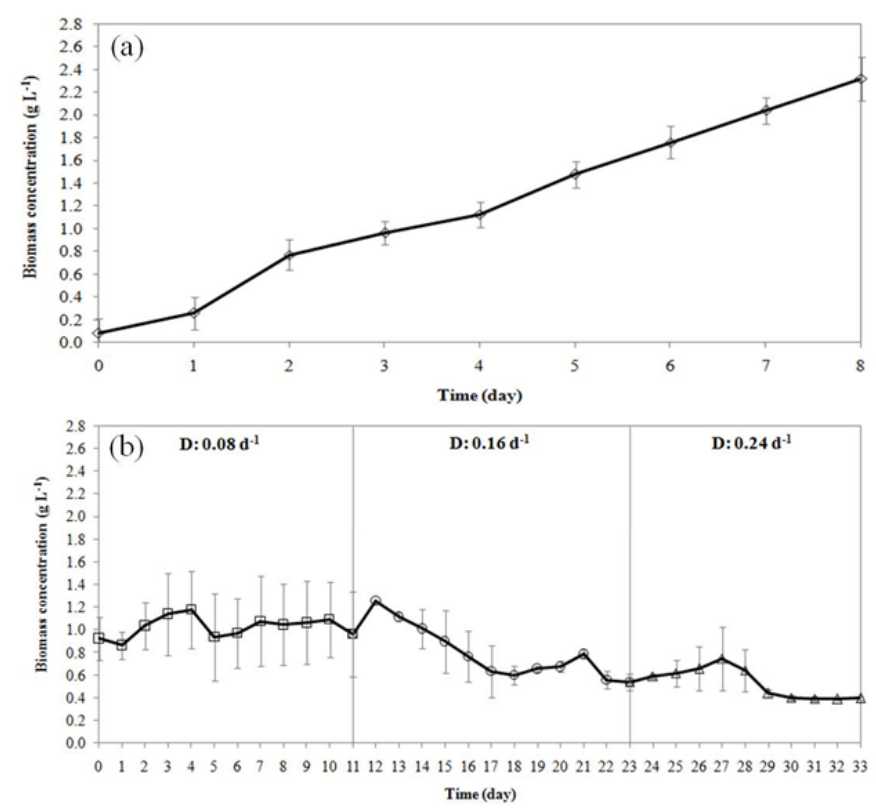

Fig. 3. Growth profile of Ankistrodesmus sp. in batch cultivation (a) and continuous cultivation (b).

TABLE I: Productivity PERFoRmance of BATCH AND CONTINUOUS

\begin{tabular}{lcc}
\hline Cultivation system & $\begin{array}{c}\text { Average biomass } \\
\text { productivity } \\
\left(\mathrm{mg} \mathrm{L}^{-1} \mathrm{~d}^{-1}\right)\end{array}$ & $\begin{array}{c}\text { Average lipid } \\
\text { productivity } \\
\left(\mathrm{mg} \mathrm{L}^{-1} \mathrm{~d}^{-1}\right)\end{array}$ \\
\hline Batch cultivation & 279.80 & 87.10 \\
\hline Continuous cultivation & & \\
Dilution rate $\left(\mathrm{d}^{-1}\right)$ : & & \\
0.08 & 82.12 & 32.72 \\
0.16 & 131.05 & 46.17 \\
0.24 & 114.00 & 42.59 \\
\hline \hline
\end{tabular}

Biomass and lipid productivities obtained for the batch cultivation and the continuous cultivation are summarized in Table I. Both biomass and lipid productivities from the batch cultivation ( 279.80 and $87.10 \mathrm{mg} \mathrm{L}^{-1} \mathrm{~d}^{-1}$ ) were always higher than those obtained from the continuous cultivation (131.05 and $46.17 \mathrm{mg} \mathrm{L}^{-1} \mathrm{~d}^{-1}$ obtained from the operation at the dilution rate of $\left.0.16 \mathrm{~d}^{-1}\right)$. Batch culture was therefore selected for further examination in this work.

\section{B. Effect of pH on Lipid Production}

The cultivation of Ankistrodesmus sp. was subject to the $\mathrm{pH}$ adjustment environment where the $\mathrm{pH}$ controller was connected to the $\mathrm{CO}_{2}$ feeding pump to control the $\mathrm{pH}$ of the nutrient at the set point. The results are displayed in Fig. 4 where the maximum biomass at $\mathrm{pH}$ 6, 7, 8 and control (no $\mathrm{pH}$ 
control) were $1.34,1.35,1.50$ and $1.23 \mathrm{~g} \mathrm{~L}^{-1}$. The biomass yield showed a slightly increasing trend with an increase in $\mathrm{pH}$. Within the range of $\mathrm{pH}$ examined in this work, the operation under $\mathrm{pH} 8$ seemed to give the best performance, however, as an overall observation, the effect of $\mathrm{pH}$ did not seem to be significant. Lipid productivity also seemed to be best induced at $\mathrm{pH} 8$ as demonstrated in Fig. 5 where the lipid content of $29.30,32.85,31.13$ and $32.09 \%$ was observed from the cultures at $\mathrm{pH} 6,7,8$ and control, respectively.

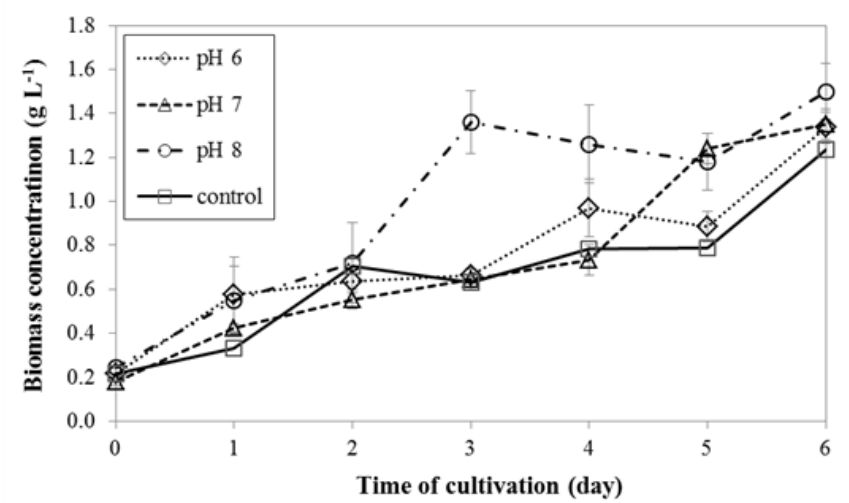

Fig. 4. Growth profile of Ankistrodesmus sp. under controlled $\mathrm{pH}$ condition.

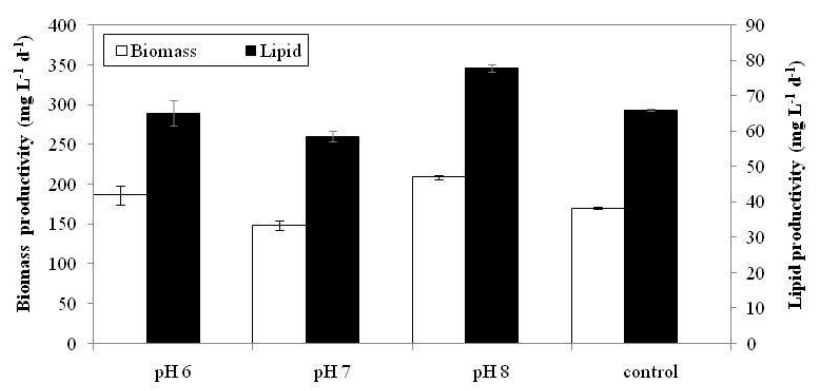

Fig. 5. Biomass productivity and lipid productivity from $\mathrm{pH}$ control experiments.

\section{Effect of Carbon Dioxide Supplement on Lipid Production}

Ankistrodesmus sp. was cultured with air at the flow rate of $1.5 \mathrm{~L}$ min $^{-1}$ mixed with $\mathrm{CO}_{2}$ gasat various volume compositions, i.e. $1 \%\left(15 \mathrm{cc} \mathrm{min}^{-1}\right), 2 \%\left(30 \mathrm{cc} \mathrm{min}^{-1}\right), 5 \%(75$ $\left.\mathrm{cc} \min ^{-1}\right)$ and $10 \%\left(150 \mathrm{cc} \mathrm{min}^{-1}\right)$, and the resulting growth curves are presented in Fig. 6. In all experiments, the culture started with the initial cell concentration of $0.2 \mathrm{~g} \mathrm{~L}^{-1}$ (approximately $1.2 \times 10^{6}$ cells $\mathrm{mL}^{-1}$ ). Cell growth was found to vary steadily with $\mathrm{CO}_{2}$ addition range of 1 to $5 \%$, after which no further positive effect of $\mathrm{CO}_{2}$ was observed. And $10 \%$ did not increase significantly. Maximum biomass yield was obtained at the end of the experiment with $5 \% \mathrm{CO}_{2}$ at $2.91 \mathrm{~g} \mathrm{~L}^{-1}$ whereas the cell growths with $1 \%, 2 \%$ and $10 \%$ were $1.79,1.97$ and $2.15 \mathrm{~g} \mathrm{~L}^{-1}$, respectively.

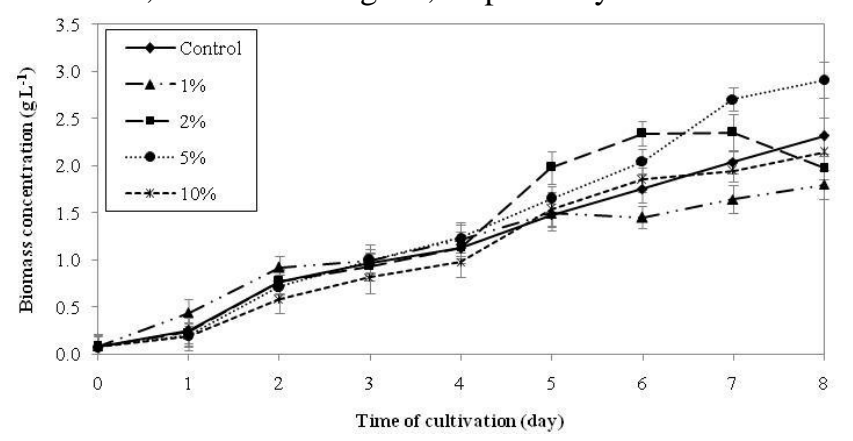

Fig. 6. Growth profile of Ankistrodesmus sp. under $\mathrm{CO}_{2}$ supplement.
The lipid content of 27.14, 31.38, 28.70 and $27.29 \%$ was observed for the culture with $\mathrm{CO}_{2}$ concentration of $1 \%, 2 \%, 5 \%$ and $10 \%$, respectively. This also suggested that maximum lipid production was obtained at $\mathrm{CO}_{2}$ supplement of $5 \%$. The biomass and lipid productivitiesare summarized in Fig. 7 where the maximum of $355 \mathrm{mg} \mathrm{L} \mathrm{d}^{-1}$ and $104 \mathrm{mg} \mathrm{L} \mathrm{d}^{-1}$, respectively, were observed at $5 \% \mathrm{CO}_{2}$.

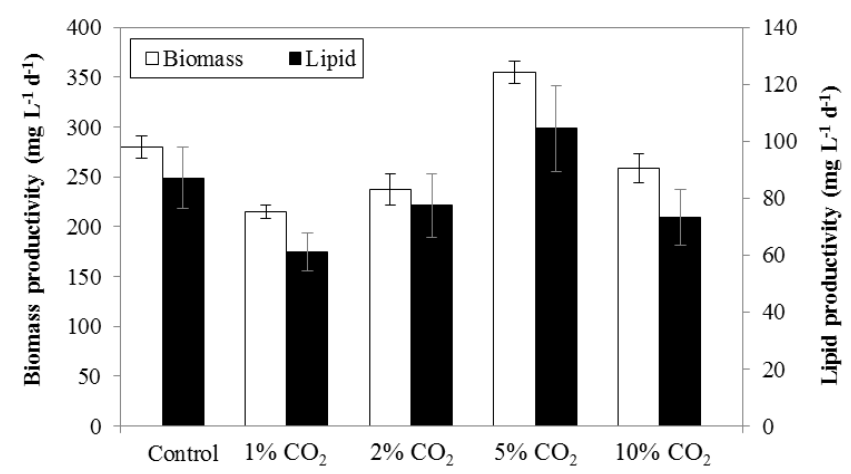

Fig. 7. Biomass productivity and lipid productivity for the culture with $\mathrm{CO}_{2}$ supplement.

\section{Fatty Acids Profile}

The fatty acid productivity profiles obtained from the cultivation of Ankistrodesmussp. under various operating conditions as examined in this work are presented in Fig. 8.

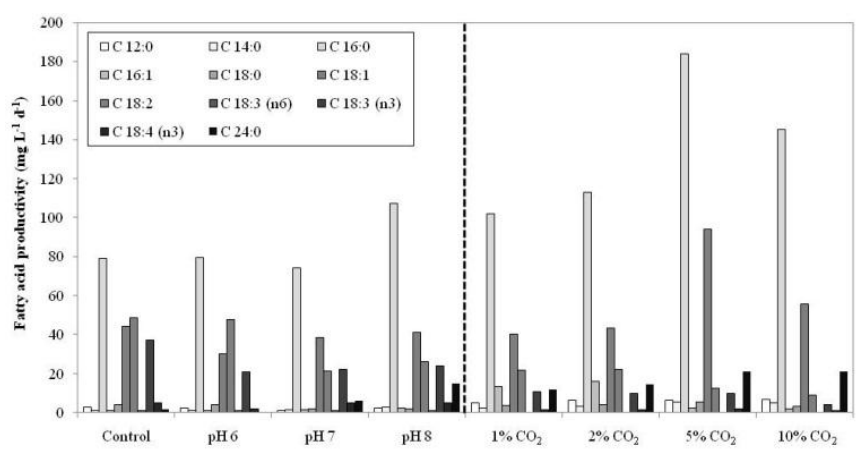

Fig. 8. Comparison of fatty acid productivity profiles from the cultivation at various conditions.

This demonstrates that the main fatty acids found from this specific culture were lauric acid (C12:0), myristic acid (C14:0), palmitic acid (C16:0), palmitoleic acid (C16:1), stearic acid (C18:0), oleic acid (C18:1), linoleic acid (C18:2), gamma linolenic acid (C18:3 ( $\omega 6)$ ), alpha linolenic acid $(\mathrm{C} 18: 3(\omega 3))$, stearidonic acid $(\mathrm{C} 18: 4(\omega 3))$, lignoceric (C24:0) were analyzed among all the conditions. Among all, Palmitic acid (C16:0) was the major fatty acid. Palmitic acid productivity increased with increase in carbon dioxide concentration up to $5 \% \mathrm{CO}_{2}$ where the highest palmitic acid productivity was obtained. The fatty acid productivity from the $\mathrm{pH}$ controlled experiments seemed to be lower than those obtained from the carbon dioxide supplementing experiments.

\section{CONCLUSIONS}

The system of cultivation plays important role in cell growth of Ankistrodesmus sp. The highest biomass productivity reached $279.80 \mathrm{mg} \mathrm{L}^{-1} \mathrm{~d}^{-1}$ in batch cultivation which was greater than the productivities attainable from the continuous cultures. The $\mathrm{pH}$ may be regulated and kept at a 
fixed level by automatic $\mathrm{CO}_{2}$ feeding where $\mathrm{pH} 8$ seemed to be best for the algal biomass production. However, the effect of $\mathrm{pH}$ was only slight and might not justify the cost of regulation. Supplying extra carbon dioxide to the system seemed to give satisfactory results when growth and lipid were to be maximized. At 5\% carbon dioxide supplement, the culture seemed to grow best and also provided the highest productivity of fatty acid. Analysis of fatty acid profiles proved that the fatty acid accumulation under $\mathrm{CO}_{2}$ addition was suitable and could be targeted for bio-diesel production.

\section{ACKNOWLEDGMENT}

Author is thankful to Biochemical Engineering Research Laboratory, Department of Chemical Engineering, Faculty of Engineering, Chulalongkorn University for providing facilities to carry out the research work.

\section{REFERENCES}

[1] A. Demirbas and M. F. Demirbas, "Importance of algae oil as a source of biodiesel," Energy Conversion and Management, vol. 52, pp. 163-170, 2011

[2] I. Maeda, Y. Seto, S. Ueda, C. G. Yukoh, J. Hari, M. Kawase, H. Miyasaka, and K. Yagi, "Simultaneous control of turbidity and dilution rate through adjustment of medium composition in semi-continuous Chlamydomonas cultures," Biotechnology and Bioengineering, vol. 94 pp. 722-729, 2006.

[3] P. P. Lamers, C. C. W. Laak, P. S. Kaasenbrood, J. Lorier, M. Janssen, R. C. H. De Vos, R. J. Bino, and R. H. Wijffels, "Carotenoid and fatty acid metabolism in light-stressed Dunaliellasalina," Biotechnology and Bioengineering, vol. 106, pp. 638-648, 2010.

[4] H. Y. Tang, N. Abunasser, M. E. D. Gaecia, M. Chen, K. Y. S. Ng, and S. O. Salley, "Potential resource of microalgae oil for biofuels feedstock production: Dunaliellatertiolecta," Applied Energy, vol. 88, pp. 3324-3330, 2011.

[5] T. M. Mata, A. A. Martins, and N. S. Caetano, "Microalgae for biodiesel production and other applications: A review," Renewable and Sustainable Energy Reviews, vol. 14, pp. 217-232, 2010.

[6] T. Jayanta, K. M. Chandra, and G. B. Chandra, "Growth, total lipid content and fatty acid profile of a native strain of the freshwater oleaginous microalgae Ankistrodesmusfalcatus (Ralf) grown under salt stress condition," International Research Journal of Biological Sciences, vol. 1, pp. 27-35, 2012.

[7] I. A. Nascimento, S. S. I. Marques, I. T. D. Cabanelas, S. A. Pereira, J. I. Druzian, C. O. Souza, D. V. Vich, G. C. Carvalho, and M. A. Nascimento, "Screening microalgae strains for biodiesel production: lipid productivity and estimation of fuel quality based on fatty acids profiles as selective criteria," BioEnergy Research, vol. 6, pp. 1-13, 2013.

[8] M. A. Salim, "The growth of Ankistrodesmus $\mathrm{Sp}$. in response to $\mathrm{CO}_{2}$ induction," Journal of Asian Scientific Research, vol. 3, pp. 75-84, 2013.

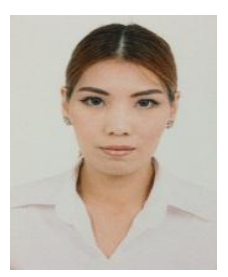

Katesuda Sukkrom was born on July 28, 1983 in Nakhon Pathom. She has her first degree in chemistry from the Faculty of Science, King Mongkut's University of Technology Thonburi and master's degree in environmental technology and management, Faculty of Science at Kasetsart University. Currently, she is a PhD student in environmental technology at the Joint Graduate School of Energy and Environment, King Mongkut's University of Technology Thonburi, Bangkok, Thailand. The paper published in International Proceedings of Chemical, Biological and Environmental Engineering (IPCBEE) is Study of Increasing Lipid Production from Reused Medium for Ankistrodesmus sp. Culture.

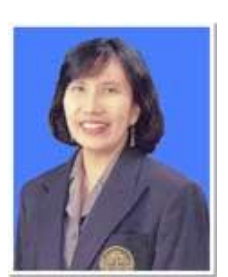

Boosya Bunnag has her first degree in microbiology from the Faculty of Science, Kasetsart University and master's degree in food science and technology at Texus A\&M University. She is an associate professor in biotechnology at the Faculty of Bioresources and Technology, King Mongkut's University of Technology Thonburi (KMUTT), Bangkok, Thailand. She is the director at the Pilot Plant Development and Training Institute (PDTI). Her major research interest is algal biotechnology. She has many publications, i.e. LCA: A Decision Support Tool to Evaluate Environmental Impacts of Sustainable MSW Management, Mass Cultivation and Genetic Studies of Cyanobacteria; Spirulina platensis, and Photosynthetic Characterization of a Mutant of Spirulina platensis. She got an award on the Natural Resources and Environmental Management.

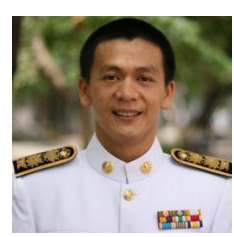

Prasert Pavasant is an associate professor in chemical engineering at the Department of Chemical Engineering, Faculty of Engineering, Chulalongkorn University, Bangkok, Thailand. He has a long experience in the field of bioreactor design including the design of photobioreactors for the cultivation of algae. His professional fellowships include the work as research directors at the Center of Excellence on Environmental and Hazardous Waste Management, Chulalongkorn University (or its new name of Center of Excellence on Hazardous Substance Management), the National Nanotechnology Center (NANOTEC), National Science and Technology Development Agency (NSTDA), and the vice director of the Research and Researcher Development for Industry Project, the Thailand Research Funds (TRF). 